\title{
EVENTOS/
}

\section{PARLAMENTO INDÍGENA DE AMÉRICA (PIA) SE REÚNE EN NICARAGUA}

\author{
Equipo Wani
}

El Parlamento Indígena de América (PIA) celebró en Managua -en la Asamblea Nacional-, durante los días ocho y nueve de abril del presente año, su décima tercera sesión plenaria y el seminario internacional "Soberanía Alimentaria”. En dicha sesión se evaluó: la presencia indígena en los parlamentos de Abya Yala; los avances de legislación y fiscalización en temas vinculados a la soberanía alimentaria (tierra, agua, semillas, subsidios y créditos, comercio justo e infraestructura productiva); los aportes en la legislación de la consulta previa y consulta pre legislativa; el pluralismo político, legislación, coordinación y cooperación de la jurisdicción indígena y ordinaria, y el estado actual de la judicialización de la movilización social. Cabe destacar también la presentación que hicieron dirigentes territoriales de la RAAS y la RAAN, sobre el avance y retos del proceso de demarcación territorial y autonomía en el Caribe nicaragüense.

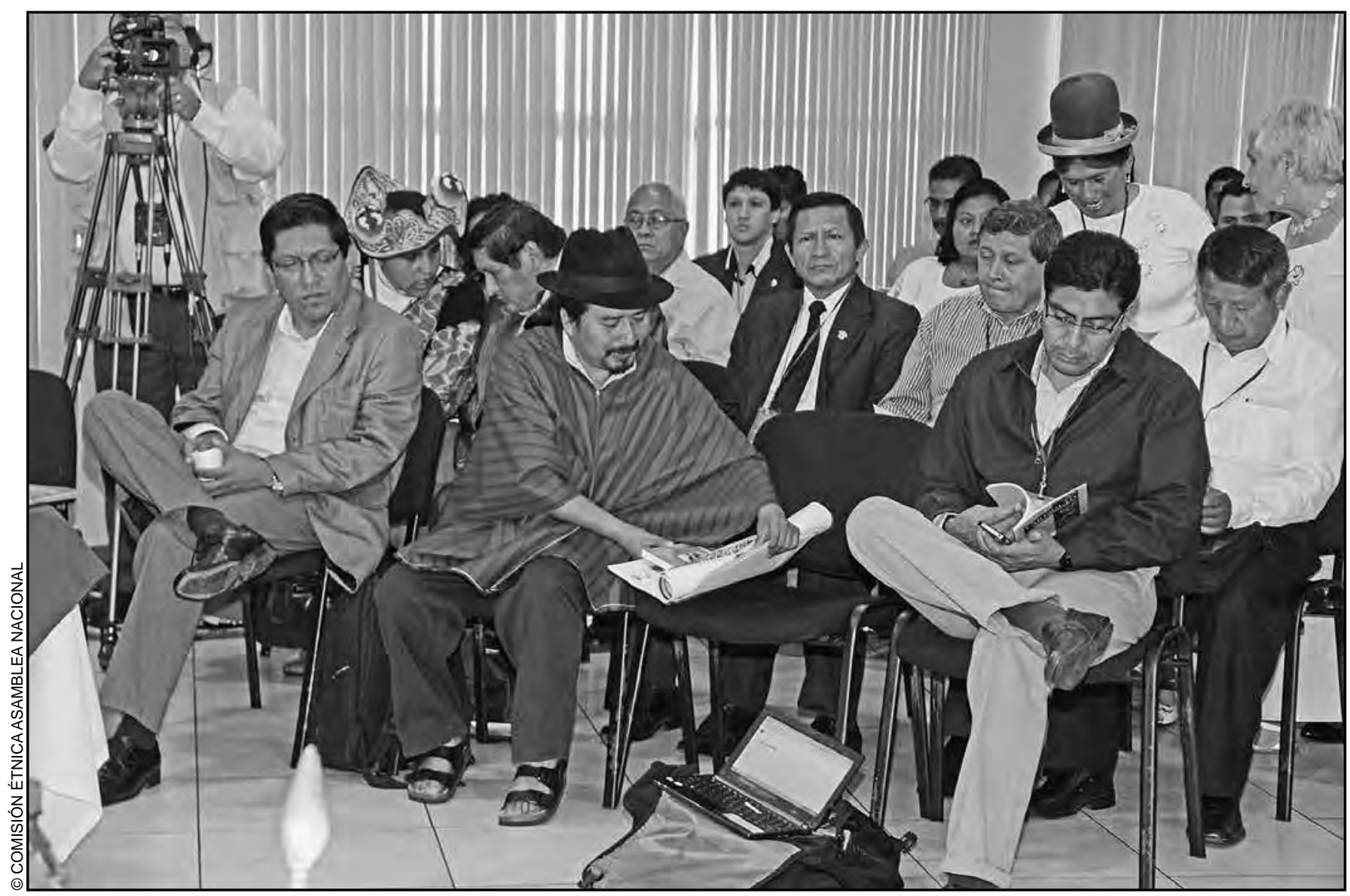

Parlamentarios indígenas de América (PIA) asistentes a la sesión celebrada en Nicaragua. 


\section{CONCLUSIONES Y RECOMENDACIONES DEL SEMINARIO}

En cada uno de los temas señalados anteriormente, las discusiones versaron sobre su importancia para los pueblos indígenas, las afectaciones que causan a los mismos y las acciones a realizar en su defensa.

\section{Soberanía alimentaria}

Temática: relación que existe entre soberanía vs. seguridad alimentaria; productos y semillas ancestrales; introducción de semillas con transgénicos en los territorio indígenas, y la moratoria a la introducción de este tipo de semillas.

Afectaciones: contaminación de semillas; dependencia de empresas transnacionales; destrucción y desaparición de semillas propias, y pérdida del poder comunitario.
Acciones a emprender: legislación y fiscalización para prevenir y evitar la introducción de transgénicos.

\section{Extractivismo}

Temática: depredación de elementos naturales, minería, hidrocarburos, hidroeléctricas, desplazamiento, contaminación.

Afectaciones: derechos colectivos, empobrecimiento y contaminación de territorios indígenas, usufructo de empresas mineras públicas y privadas.

Acciones a emprender: legislación para garantizar los derechos de la madre tierra y de los pueblos indígenas, fiscalizar la afectación de derechos, modelo de desarrollo del sumak kawsay.

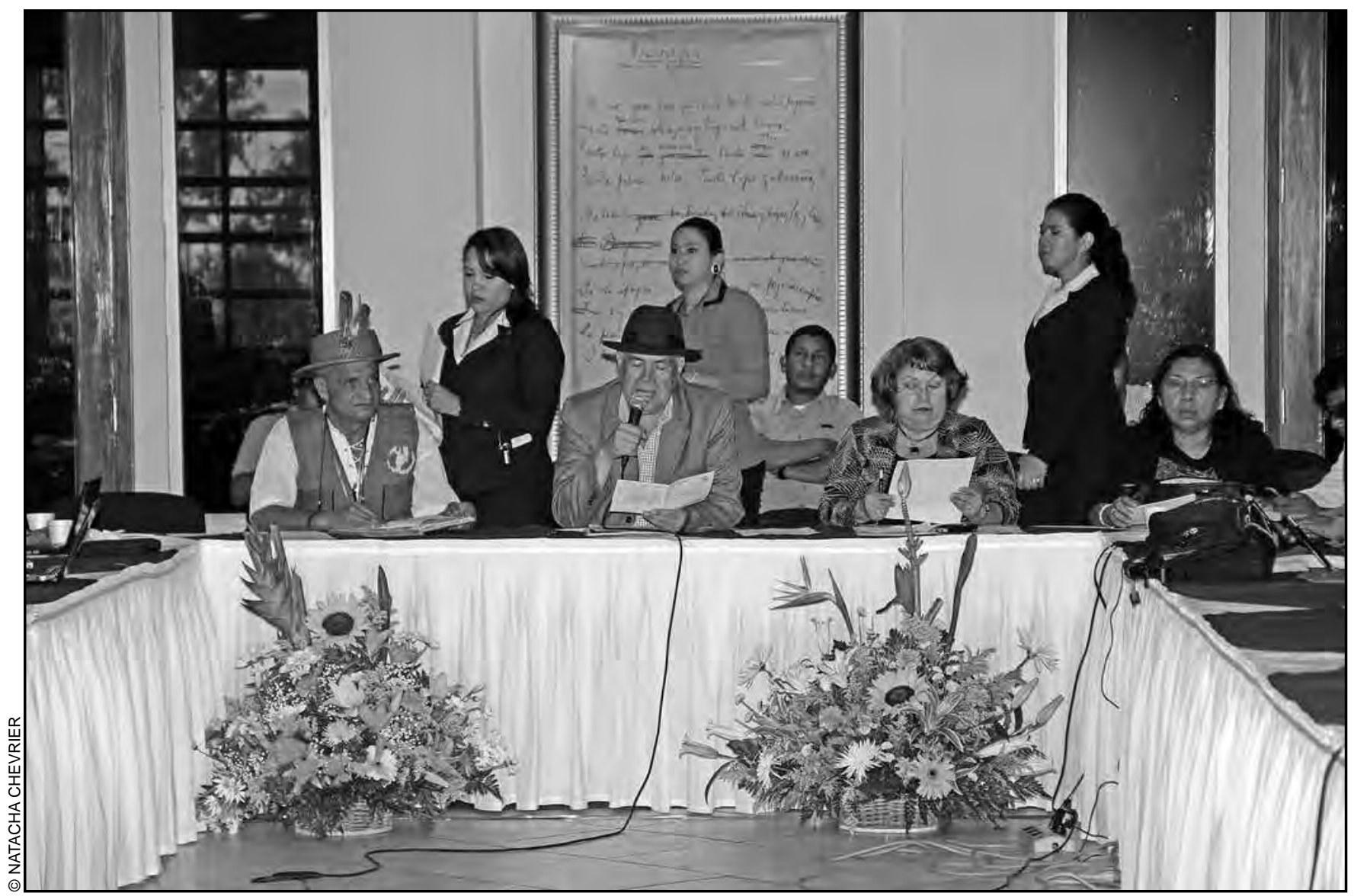

Brooklin Rivera, parlamentario anfitrión, acompañado del presidente del PIA, diputados de la Asamblea Nacional y autoridades autónomas del Caribe. 


\section{Consulta previa y pre legislativa}

Temática: ejercicio de derechos de los pueblos, marco jurídico, aplicación incipiente, consentimiento previo o vinculancia.

Afectaciones: imposición de normas, contratos y prioridades del Estado.

Acciones a emprender: acciones afirmativas, legislación, fiscalización de afectación de derechos comunitarios.

\section{Autonomías de comunidades, pueblos y nacionalidades}

Temática: posesión ancestral, tierra y territorio, demarcación territorial, legalización de la propiedad comunitaria.

Afectaciones: apropiación, expulsión.

Acciones a emprender Legislación, reformas, inversión del Estado, programas sociales y económicos.

\section{Madre tierra}

Temática: la tierra como ente vivo tiene vida, como madre de los seres vivientes.

Afectaciones: armonía y equilibrio, regeneración de componentes de vida, saberes comunitarios, planificación y gestión.

Acciones a emprender: legislar para el vivir bien, armonía y vida del todo, autoridad para vivir bien.

\section{Otras recomendaciones}

Dialogo de saberes en el ámbito legislativo y de fiscalización de forma colectiva.

Generar los marcos jurídicos para el pleno ejercicio de los derechos de los pueblos y la naturaleza, semillas, tierras y territorios, agua, consulta, autonomías, actividades extractivas, vivir bien-sumak kawsay.

Promover observatorios de la afectación de los derechos en cada uno de los pueblos y países.

Definir mecanismos de intercambio en el marco del PIA.

\section{NICARAGUA, SEDE DE LA SECRETARÍA TÉCNICA DEL PARLAMENTO INDÍGENA DE AMERICA}

El resultado más importante y concreto para los pueblos indígenas y la comunidad afrodescendiente de Nicaragua fue la resolución X, por la cual se instaura en Nicaragua la Sede de la Secretaría Técnica del Parlamento Indígena de América (PIA). Esta resolución amplía el marco de posibilidades reivindicativas de los pueblos indígenas y las comunidades étnicas de Nicaragua. A continuación presentamos dicha resolución.

\section{RESOLUCIÓN \\ PARLAMENTO INDIGENA DE AMERICA (PIA)}

Por la cual se instaura la Sede de la Secretaria Técnica del Parlamento Indígena de América (PIA) en la ciudad de Managua, Nicaragua.

\section{Considerando:}

1. Que durante la Segunda Asamblea General del Parlamento Indígena de América (PIA) celebrada en Managua, Nicaragua, del 29 al 31 de agosto de 1988 se creó la Secretaria y Subsecretaría Permanente del PIA.

2. Que desde 1990 hasta el año 2000, la Secretaría Permanente fue coordinada por la Asamblea Nacional de la República de Nicaragua asumiendo como parte de su quehacer el apoyo incondicional a los fines y objetivos perseguidos por el Parlamento Indígena de América para su funcionamiento.

3. Que el dinamismo presentado por la Secretaría Permanente durante esta década fue un período en el cual el Parlamento Indígena de América alcanzó singular presencia como el espacio político social donde se abordaron y promovieron la restitución de derechos y soluciones para los problemas que afectan a los pueblos indígenas.

4. Que los pueblos originarios en seno del PIA tienen todo el derecho a contar con su Secretaria Permanente a efectos de continuar avanzando en el fortalecimiento de su gestión. 


\section{Resuelve}

1. Instaurar la Sede de la Secretaría Técnica en la ciudad de Managua, Nicaragua de forma permanente con la finalidad de continuar dinamizando y fortaleciendo al Parlamento Indígena de América, creando estructuras cada vez más sólidas, así como mecanismos que permitan la articulación de sus objetivos comunes y respuestas en beneficio de los pueblos indígenas.

2. La Secretaria Permanente por su interlocución natural estará adscrita y bajo el apoyo y coordinación de la
Presidencia del PIA y la Comisión Parlamentaria de Asuntos de los Pueblos Indígenas, Afro descendientes y Regímenes Autonómicos de la Asamblea Nacional de Nicaragua.

3. La Secretaria Permanente debe estar dirigida por un genuino representante y conocedor de los temas de los pueblos indígenas u originarios, apoyado por un equipamiento básico humano y material.

Dado en la Décimo Tercera Sesión del Parlamento Indígena de América celebrada en la Asamblea Nacional de Nicaragua los días 8 y 9 de abril del año 2013.

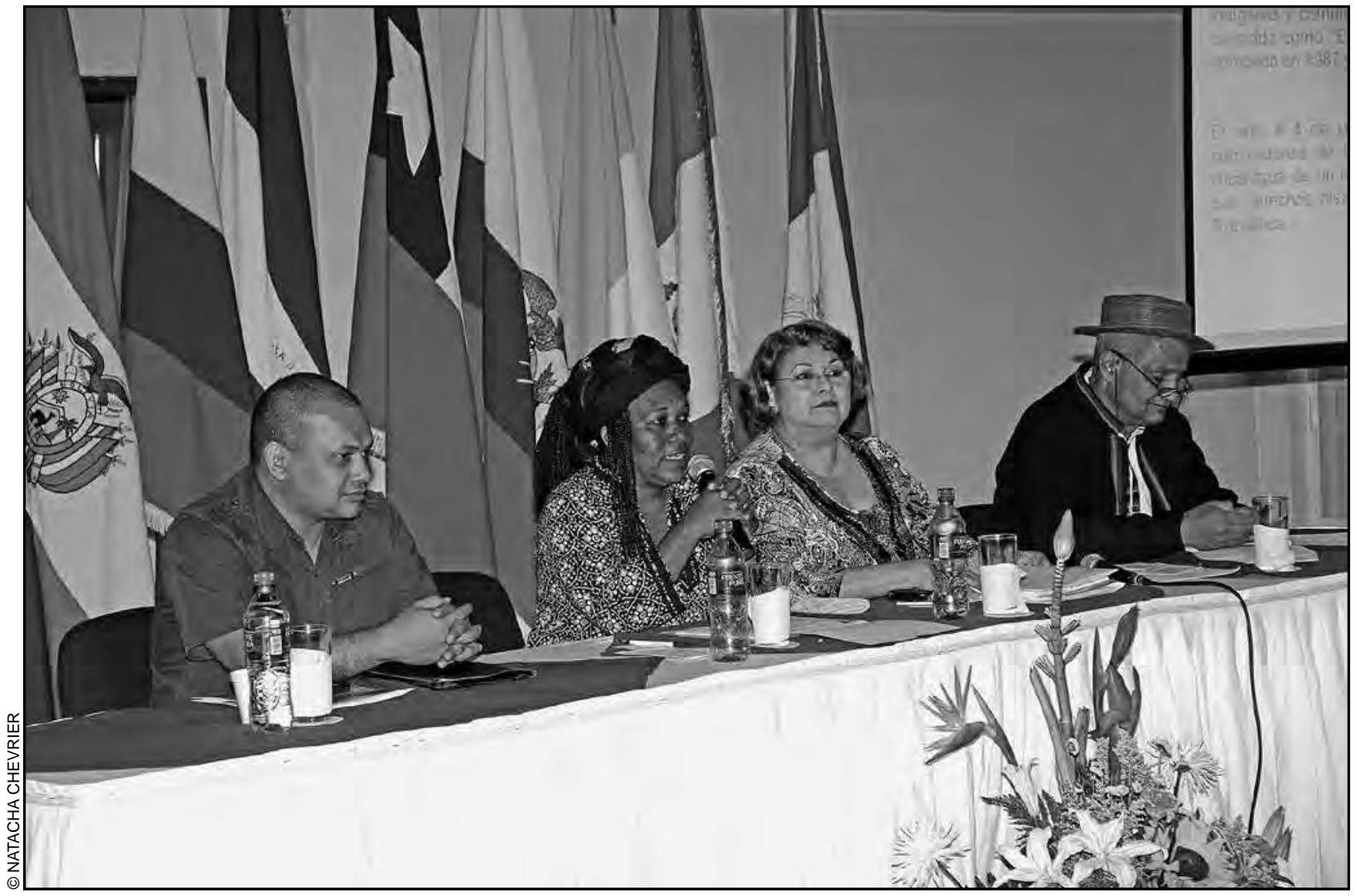

Carlos Alemán, presidente del CRAAN, diputados nacionales y del PIA. 